\title{
A INFLUÊNCIA DO SUPORTE ORGANIZACIONAL NO DESEMPENHO PROFISSIONAL DOS COLABORADORES ${ }^{1}$
}

\author{
THE INFLUENCE OF ORGANIZATIONAL SUPPORT ON THE \\ PROFESSIONAL PERFORMANCE OF EMPLOYEES
}

\author{
Gabrieli Deprá2 ${ }^{2}$ Lucas Almeida dos $\operatorname{Santos}^{3}$ e Janaina Marchi ${ }^{4}$
}

\section{RESUMO}

O presente estudo que tem como objetivo investigar como o suporte organizacional influencia no desempenho profissional dos colaboradores de uma empresa de entretenimento da região de Central do Rio Grande do Sul apresenta-se como um estudo de caso, de natureza qualitativa, descritiva e teórico comparativa, tendo seus dados coletados por meio da técnica de observação de forma sistemática, observando-se desde a estrutura organizacional, as práticas de suportes ofertadas, bem como a forma como as tarefas são realizadas. Como principais resultados, observou-se que a percepção do suporte organizacional na empresa em análise, ancora-se nos termos de equipamentos, máquinas e materiais, além da percepção de condições estruturais, estando limitado no que diz respeito à saúde, desenvolvimento e carreira e treinamentos. Quanto à avaliação de desempenho profissional, está encontra-se atrelada a recompensa financeira, sendo os colaboradores avaliados pelo alcance de metas e pela execução de atividades diárias. Ademais, conclui-se que a empresa possui alguns pontos fracos ligados rotinas de trabalho, já que as avaliações não foram satisfatórias no fator treinamento, saúde, desenvolvimento e carreira. Assim, sugere-se para a empresa, a elaboração de um planejamento estratégico voltado para a gestão de pessoas, o qual inclua ações estratégicas que transformem estas fragilidades em pontos fortes.

Palavras-chave: Gestão de Pessoas, Suporte Organizacional, Desempenho Profissional.

\section{ABSTRACT}

The present study, which aims to investigate how organizational support influences the professional performance of employees of an entertainment company in the Central region of Rio Grande do Sul, presents itself as a case study, of a qualitative, descriptive and comparative theoretical nature, having their data collected through the observation technique in a systematic way, observing from the organizational structure, the practices of supports offered, as well as the way the tasks are performed. As main results, it was observed that the perception of organizational support in the company under analysis, is anchored in terms of equipment, machines and materials, in addition to the perception of structural conditions, being limited with regard to health, development and career and trainings. As for the assessment of professional performance, financial reward is linked, with employees being assessed for achieving goals and carrying out daily activities. In addition, it is concluded that the company has some weaknesses linked to work routines, since the evaluations were not satisfactory in the training, health, development and career factor. Thus, it is suggested for the company, the elaboration of a strategic planning focused on people management, which includes strategic actions that transform these weaknesses into strengths.

Keywords: People Management, Organizational Support, Professional Performance.

1 Artigo resultante do trabalho final de graduação.

2 Aluna egressa do Curso Tecnólogo em Gestão de Recursos Humanos. E-mail: gabi.depra90@gmail.com

3 Professor Doutor em Administração da Universidade Franciscana. E-mail: lucas.almeida@ufn.edu.br

4 Professora Mestra em Administração da Universidade Franciscana. E-mail: janaina.marchi@ufn.edu.br 


\section{INTRODUÇÃO}

O mercado atual tem ficado cada vez mais competitivo, perante esta situação, as Organizações é que estão sujeitas às vontades e exigências do pessoal, cabendo a elas, o dever de motivar e reter seus colaboradores, oferecendo-os recursos motivadores (ANDRADE, 2012). Neste sentido, o trabalho influencia diretamente na vida dos indivíduos, pois grande parte dos trabalhadores buscam empresas que se importam com o seu bem-estar e desta forma o funcionário se sente valorizado aumentando assim o desempenho na execução das tarefas e processos dentro da organização (COSTA, 2015).

Sob este viés, o suporte organizacional pode condicionar o bem-estar, o qual é obtido por meio da harmonia entre o que é exigido do colaborador e a capacidade de realização. Do contrário, caso a harmonia entre esses aspectos não seja alcançada serão gerados distintos níveis de insegurança, bem como sensações de desamparo que podem atrapalhar ou dificultar o desempenho do trabalhador (ALBUQUERQUE; LIMONGI-FRANÇA, 1998).

Ademais, vale ressaltar que o suporte organizacional faz referência às percepções do trabalhador acerca da qualidade do tratamento que este recebe da organização em retribuição ao esforço que despende no trabalho, o qual reflete no desempenho do colaborador. Segundo ABBAD (1999), a organização de um lado, deseja o bom desempenho do trabalhador, enquanto este, de outro lado, espera ter seu esforço valorizado e recompensado pela organização.

Quando um colaborador atua diretamente com pessoas e no ramo de entretenimento, fatores como seu nível de satisfação perante o seu local de trabalho, humor, valorização se tornam indispensáveis na sua função. O seu propósito é proporcionar diversão aos clientes e transpassar alegria naquele momento. O termo entretenimento, do latim "inter" (entre) "tenere" (ter), evoluiu para o inglês "entertainment", "aquilo que diverte com distração ou recreação" ou "um espetáculo público ou mostra destinada a interessar ou divertir" (GABLER, 1999: 25).

Diante do exposto, o presente estudo tem como problemática de pesquisa responder o seguinte questionamento: como o suporte organizacional infuencia no desempenho profissional dos colaboradores de uma empresa do ramo do entretenimento? Assim, como forma de responder a problemática estabelecida, tem-se como objetivo geral de investigar como o suporte organizacional influência no desempenho profissional dos colaboradores de uma empresa do ramo do entretenimento.

A escolha pela empresa em estudo, sendo esta do ramo do entretenimento, remete-se, primeiramente ao fato desta estar passando por dificuldades estruturais e de pessoas, carecendo de estudos que possibilitem uma compreensão situacional da mesma e a possível proposição de práticas que auxiliem neste processo de transição. Noutro momento, o referido ramo em que a organização se encontra é palco de muitos questionamentos, afinal, esta vendendo entretenimento para os clientes, necessita ter práticas de gestão de pessoas que possibilitem um suporte organizacional que comprometa os colaboradores e facilite que estes vendam, também, uma boa imagem aos seus consumidores. 
Noutra perspectiva, a presente pesquisa ainda justifica-se devido ao fato de que a influência da percepção do suporte organizacional em alto nível pode trazer diversos benefícios para a organização, desde a redução do absenteísmo até a intenção de sair da empresa, além disso, traz aumento do desempenho, maior comprometimento e satisfação com o trabalho (SIQUEIRA; GOMIDE, 2004).

\section{REFERENCIAL TEÓRICO}

A seguir tem-se estruturado o referencial teórico acerca da temática abordada neste estudo, suporte organizacional e desempenho profissional, construídos a partir dos conceitos e pensamentos dos estudiosos e pesquisadores da área.

\section{SUPORTE ORGANIZACIONAL}

O conceito pioneiro de suporte organizacional foi proposto por Eisenberger, Huntington, Hutchinson e Sowa em 1986. Esses pesquisadores desenvolveram um instrumento (Survey of Perceived Organizational - SPO) para avaliar as percepções dos empregados quanto ao tratamento que recebem da organização e quanta preocupação há com seu bem-estar. Assim, o desenvolvimento da percepção do suporte organizacional é motivado pela tendência dos trabalhadores em atribuir à organização características humanas, sendo a percepção dos empregados acerca da qualidade do tratamento recebido, ou seja, o quanto seus esforços são valorizados e retribuídos pela organização (EISENBERGER et al., 1986).

O suporte organizacional é tido como uma variável que influencia positivamente na percepção da melhoria no relacionamento com a liderança e aumento do desempenho no trabalho (SHANOCK; EISENBERGER, 2006). Ainda, o suporte organizacional está ligado às iniciativas de desenvolver os colaboradores, promover recursos, trabalhar para que possam atuar de forma mais autônoma e promover mais visibilidade e reconhecimento para a organização (COVACS, 2006). Nessa conjuntura, Siqueira e Gomide Jr. (2004) apontam que a percepção do suporte organizacional por parte dos colaboradores pode influenciar o desempenho da organização em termos de efetividade e comprometimento.

Ainda, para Jawahar e Hemmasi (2006) e Paschoal (2008), a percepção de suporte organizacional se desenvolve através das múltiplas situações de troca existentes entre o empregado e o empregador/empresa, pois o suporte organizacional é uma forma de contrato psicológico baseado em expectativas de troca e benefícios mútuos que são estabelecidos pelo trabalhador com a sua organização. Assim, a relação entre o trabalhador e a organização está apoiada na expectativa de trocas, visando a benefícios mútuos, pois se de um lado a organização deseja o bom desempenho do trabalhador, de outro, este espera ter seu esforço valorizado e recompensado pela organização. 
Noutro sentido, o reconhecimento da importância do suporte organizacional coloca foco sobre a discussão de que o resultado apresentado pelo trabalhador ao investir em novos aprendizados não é somente fruto de suas características pessoais; está relacionado também ao quanto a organização contribui para que esse aprendizado se concretize em novos e melhores desempenhos (DOURADO, 2016). Autores como Coelho Júnior (2015) apontam que aspectos como a disponibilidade de materiais, o apoio sistemático de líderes e o contexto têm efeito direto sobre o padrão, a qualidade e o tipo de desempenho.

Por fim, a percepção quanto ao suporte organizacional ocorre quando a organização oferecer ao colaborador algumas condições essenciais, tais como: compreensão e entendimento acerca da tarefa a ser desempenhada, ou seja, o saber fazer, também é importante a motivação para laborar que nada mais é que o querer fazer e ainda, condições adequadas para o desempenho das atividades, isto é, o poder fazer (QUEIROGA BRANDÃO; BORGES-ANDRADE, 2015).

\section{DESEMPENHO ORGANIZACIONAL DOS COLABORADORES}

O desempenho (ou performance) é definido como o conjunto de características ou capacidades de comportamento e rendimento do indivíduo, e expressa a ideia de ação para o alcance de objetivos pessoais e organizacionais, passível de julgamento em termos de adequação, eficiência e eficácia, e com implicações significativas sobre o bem-estar e a satisfação (BENDASSOLLI; MALVEZZI, 2013). No entanto, Grote (2003), elucida que o desempenho é visto como a qualidade e a quantidade de trabalho executado, relacionados ao custo e ao tempo dedicados. Segundo Coelho Júnior (2015), o desempenho envolve esforços individuais voltados à execução de certos comportamentos previamente planejados e esperados, sendo este um conceito associado à consecução de resultados.

Ainda, o desempenho constitui conceito associado à consecução de resultados (SONNENTAG; FRESE, 2002). Expressa a ideia de ação para alcance de objetivos, passível de julgamento em termos de adequação, eficiência e eficácia (ABBAD, 1999). Ainda, o desempenho de uma organização (ou de suas unidades) refere-se aos resultados por ela alcançados em certo período (FERNANDES; FLEURY; MILLS, 2006), o que pode ser avaliado por meio de parâmetros quantificáveis denominados indicadores.

Neste viés, o desempenho organizacional é mensurado comparando-se os resultados obtidos pela organização com as metas previamente estipuladas para cada indicador (BRANDÃO; GUIMARÃES, 2001). No entanto, diversos critérios de desempenho podem ser utilizados para a definição de indicadores e metas, tendo em vista os múltiplos efeitos que a atuação de uma organização pode gerar nos ambientes interno e externo. Lucratividade, produtividade, qualidade e satisfação do cliente são critérios comumente utilizados (CARBONE et al., 2009).

Nesta esteira de pensamento, Slater, Olson e Hult (2010) definem desempenho como o atingir dos objetivos estabelecidos pela organização ou a superação destes, podendo ser avaliado por aspectos financeiros, de mercado e/ou inovação. Ainda, o desempenho organizacional é avaliado por meio 
de um sistema de informações que os gestores usam para rastrear a implementação das estratégias estabelecidas pela organização, comparando os resultados reais aos objetivos e metas estratégicas estabelecidas (SIMONS, 2000).

Ainda, o desempenho organizacional é mensurado a partir de indicadores, que devem estar conectados às estratégias e competências estabelecidas pela organização (KAPLAN; NORTON, 1997). Segundo Simons (2000), o propósito da criação de indicadores capazes de relatar o desempenho das organizações é a transmissão de informações financeiras e não financeiras.

Para Kaplan e Norton (1997), os indicadores de desempenho requerem visão holística da organização. Todos os envolvidos precisam estar motivados para implementar as estratégias com vistas no resultado global da organização. Os indicadores precisam ser facilmente transmitidos, as metas devem ser previamente definidas e os resultados devem ser compartilhados, a fim de que as organizações consigam alinhar suas estratégias.

\section{METODOLOGIA}

O presente estudo que tem como objetivo investigar como o suporte organizacional influência no desempenho organizacional dos colaboradores de uma empresa de entretenimento na região de Santa Maria Rio Grande do Sul, trata-se de um estudo de caso, pois irá se aprofundar em um caso único. Logo para Yin (2001), o estudo de caso como uma estratégia de pesquisa que responde às perguntas "como" e "por que" e que foca em contextos da vida real de casos atuais.

Quanto à natureza trata-se de uma pesquisa qualitativa, pois pretende-se compreender e descrever de que forma um bom suporte ofertado pela organização afeta e influencia no dia a dia do indivíduo dentro do ambiente de trabalho. Assim, na concepção de Cooper e Schindler (2016), a pesquisa qualitativa inclui um conjunto de técnicas interpretativas que procuram descrever, modificar, traduzir e, de outra forma, aprender o significado, e não a frequência de certos fenômenos que ocorrem de forma mais ou menos natural na sociedade, visando atingir o entendimento profundo de uma situação.

De acordo com os objetivos, o presente estudo classifica-se como uma pesquisa descritiva, pois foi feito uma descrição da realidade do suporte no ambiente organizacional com o escopo de identificar os fatores que possibilitam um maior desempenho profissional do indivíduo na organização. Para Gil (2019), as pesquisas descritivas têm como propósito identificar fatores que determinam ou contribuem para a ocorrência dos fenômenos.

Para a coleta de dados, esta se realizou por meio da técnica de observação de forma sistemática, observando-se desde a estrutura organizacional, as práticas de suportes ofertadas, bem como a forma como as tarefas são realizadas. Segundo Zanelli (2002), a observação atenta dos detalhes coloca o pesquisador dentro do cenário de forma que ele possa compreender a complexidade dos ambientes, ao mesmo tempo em que lhe permite uma interlocução mais competente. 
No que tange a análise dos dados, esta ocorreu por meio da análise teórica comparativa, no qual se realizou uma comparação das práticas de gestão de pessoas voltada para o suporte que a empresa em análise oferece com o que embasa a literatura vigente. A análise teórica comparativa, na concepção de Gil Flores (1994), refere-se aos procedimentos de análise sobre dados qualitativos que partem do pressuposto de que a realidade social é múltipla, mutável e resultado da construção social. Assim, busca-se compreender e interpretar, por meio desta, como a realidade encontra-se entendida pelos participantes.

Complementando a análise teórica comparativa, os dados também foram analisados de forma descritiva, possibilitando assim, descrever e interpretar os achados por meio da observação, facilitando dessa forma, a comparação com a teoria existente.

\section{RESULTADOS E DISCUSSÕES}

Nesta seção tem-se a análise dos resultados construídos de acordo com o objetivo proposto e o método estruturado para este artigo.

\section{CARACTERIZAÇÃO DA EMPRESA}

Em primeiro momento, salienta-se que o objeto de análise deste estudo é uma empresa do ramo de vendas de produtos voltados para o entretenimento, pois além de comercializar produtos militares esta ainda possui um stand de tiros de airsoft em seu interior. Contudo, na percepção de Santana (2020) compreende-se que o entretenimento é uma forma de recrear ou divertir as pessoas ou um conjunto delas quando elas se encontram desviadas de suas preocupações cotidianas; são o ofício de captar a concentração de grupos ou de indivíduos, com a aplicação das mais variadas ocupações que visam tão somente o prazer, por um período temporal fixo ou impreciso.

Estruturalmente a empresa em questão conta com uma equipe pequena de quatro colaboradores, além dos três sócios. Seus colaboradores exercem as funções de caixa responsável, caixa, vendedor e de assistente de recreação, conforme esquematizado no organograma a seguir.

Figura 1 - Organograma da empresa em análise.

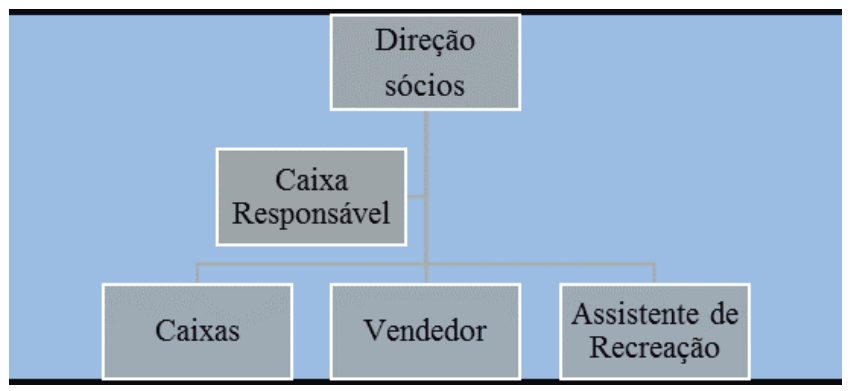

Fonte: Elaborado pelos autores. 
As responsabilidades são divididas de acordo com cada cargo, os sócios são os gestores da empresa, os mesmos ficam responsáveis pela parte de compras de mercadorias e determinação das metas e os objetivos da organização. O cargo de caixa responsável desempenha a função de monitorar os demais colaboradores, assim como treinamento e mensuração do desempenho de cada um. Ainda, o caixa responsável é quem elabora a escala mensal dos demais, controla o estoque, realiza a divisão das atividades por colaborador e realiza a abertura e fechamento dos caixas.

O caixa dois, além de efetuar atendimento aos clientes, fluxo de caixa, notas fiscais, ainda auxilia o caixa responsável em suas atividades. O vendedor e o assistente de recreação lidam mais com as vendas, um se responsabiliza pelos produtos da loja e o de recreação é responsável por tudo que acontece no stand, desde o acompanhamento e monitoramento do cliente ao entrar no stand até o controle e manutenção das armas de airsof.

No que tange os processos de gestão de pessoas, como forma de agregar pessoas, o processo de recrutamento e seleção da empresa ocorre anualmente, para suprir as necessidades das demandas de fim de ano e as férias dos demais funcionários fixos. Assim, conforme observado, o processo de agregar pessoas na organização é realizado pelos três sócios, sendo um processo prático e rápido, já que suas vagas são anunciadas em redes sociais e os currículos recebidos via e-mail. A técnica de seleção é feita por uma única entrevista com cada indivíduo selecionado e após estas, os sócios decidem qual candidato contratar, levando-se em consideração um único requisito, que é ter experiência em vendas. No entanto, salienta-se que, conforme Melo et. al. (2011), o recrutamento deve funciona como meio de comunicação onde são divulgadas as vagas para determinados cargos dentro da empresa e a seleção funciona com o papel de escolher ou dar opções a seleção, onde se decide conforme a cultura da organização e com o desempenho do candidato para o cargo oferecido.

Ainda, comercialmente a organização investe na compra de produtos mensalmente, a qual trabalha com diversas marcas, apostando nas redes sociais como forma de divulgação, pois além de vendas na loja física a organização conta com um site próprio. Neste contexto, a empresa tem como missão comercializar artigos militares de alta qualidade e ao mesmo tempo proporcionar momentos de diversão aos seus consumidores, a partir de relacionamentos sustentáveis entre pessoas e como visão, em longo prazo, de se tornar referência em artigos militares e montar uma rede de franquias em diferentes cidades do Brasil.

\section{SUPORTE ORGANIZACIONAL PERCEBIDO NA EMPRESA}

Esta seção aborda o suporte organizacional ofertado pela empresa aos seus colaboradores, por meio das práticas de gestão de pessoas, conforme observação realizada. Assim, para os gestores, estes acreditam que com confiança e autonomia podem fortalecer os laços entre eles e seus funcionários, desta forma sua equipe se sente parte do sonho, desenvolvendo seu trabalho com maior desempenho e 
comprometimento. Segundo um dos sócios, os valores da empresa baseiam-se em confiança nos seus funcionários e transparência, como uma família.

Neste viés, seus funcionários possuem liberdade para dar sugestões de melhorias até mesmo em suas remunerações. Desde a inauguração da loja, muitas mudanças interelacionais ocorreram entre colaboradores e gestores até mesmo nos benefícios financeiros oferecidos por estes. Atualmente, dentre as práticas de suporte ofertadas pela empresa, tem-se uma jornada de trabalho bastante flexível em relação aos horários, espaço organizado para as refeições, que possui micro-ondas, cafeteira, frigobar e filtro de água mineral.

A organização oferece, também, equipamentos como computadores, impressoras, máquinas de cartão em boas condições para o desempenho das funções operacionais de cada atividade desempenhada pelo colaborador. Os recursos de comunicação utilizados pela empresa são e-mail e whatsapp, a mesma possui um grupo no whatsapp com todos os membros da empresa, no qual é usado para informar escalas, resolução de problemas e para manter os sócios mais próximos aos funcionários.

Ainda, dentro da atividade de recreação, é realizado um treinamento do funcionário responsável, pois o mesmo ao atender os clientes no stand, repassa seus conhecimentos e cuidados da área e neste sentido necessita sentir-se preparado para exercer suas atividades, passando maior credibilidade ao cliente. Porém, por outro lado percebe-se que os demais colaboradores sentem falta de treinamentos ofertados pela própria organização para que possam, também, desenvolver suas atividades com maior eficiência.

Outro ponto percebido foi quanto a remuneração da equipe, a qual conta com um salário, vale transporte, vale alimentação e comissões sobre as vendas. As comissões são de acordo com o quanto a loja fatura no mês, portanto, quanto mais unida a equipe estiver maior serão os resultados da organização e maior será a remuneração, ou seja, este fator depende totalmente do desempenho organizacional de cada um dentro da equipe. Nota-se no presente estudo, que a empresa não costuma ofertar suportes voltados a qualidade de vida do funcionário, como assistência à saúde, suporte psicológico, incentivos aos esportes. Desta forma, sugere-se à empresa rever a importância dos mesmos para os colaboradores, de tal forma que estes suportes possam aumentar o engajamento de sua equipe.

Neste sentido, conforme observado, pode-se arguir que ocorre uma troca, ou seja, os gestores oferecem recompensas e um bom ambiente organizacional em troca de resultados que estes consideram satisfatórios, pois segundo estes, um sistema de recompensas, independentemente do seu tipo, procura demonstrar o quanto vale um indivíduo para a organização.

\section{DESEMPENHO PROFISSIONAL}

Neste tópico, aborda-se acerca da avaliação de desempenho organizacional, ou seja, uma descrição das práticas observadas na empresa em análise, levando-se em consideração o suporte prestado 
pela mesma. Assim, compreendeu-se que avaliação de desempenho utilizada na empresa em análise é realizada por competências, na qual, por meio de uma análise sistemática é mensurada a contribuição e a realização das tarefas de acordo com cada função. Tal ação adotada pela empresa vai ao encontro do proposto por PONTES (1999), o qual aborda que a avaliação de desempenho é um método que visa, continuamente, a estabelecer um contrato com os funcionários referente aos resultados desejados pela organização, busca ainda, acompanhar os desafios propostos, corrigindo os rumos, quando necessário, e avaliar os resultados conseguidos.

Por conseguinte, os feedbacks por parte da gerência ocorrem sempre que necessários, para que os funcionários saibam no que precisam melhorar em relação ao seu desempenho perante a organização. Neste sentido, Ribeiro (2005), destaca que a avaliação de desempenho é o momento esperado pelo funcionário para que alguém fale de seu desempenho e direcione suas próximas ações.

Assim, conforme observado, a empresa utiliza-se de ferramentas gerenciais para mensurar o desempenho dos colaboradores. Os exemplos disso, os relatórios de vendas da organização exibem o desempenho individual de cada funcionário, ou seja, quem se destaca nas vendas e quem ainda precisa melhorar. Ainda, estes relatórios são integrados e cabe aos funcionários preencherem semanalmente os formulários, especificando nestes os setores que necessitam de reabastecimento. Desta forma os gestores conseguem controlar a distribuição das atividades, mensurando o desempenho de cada um de acordo com a função desempenhada.

De forma geral, ao que se percebe, a empresa optou por estabelecer metas gerais, para incentivar a união e a colaboração de todos, porém, para que se possa mensurar ainda mais o desempenho, sugere-se a implantação de metas individuais que demostrem o quanto o esforço de cada um pode ser retribuído individualmente e gere uma motivação para a busca de se melhorar dentro das atividades prestadas.

Ainda sobre as metas, observou-se que estas são estipuladas pelos sócios, os quais levam em consideração o mês atual e o quanto foi vendido no mês anterior, como forma de estipular quantitativamente o que cada colaborador terá que atingir. Estrategicamente, com o intuito de promover a superação e alcance das metas estipuladas, os sócios condicionam metas maiores, como forma de estimular um maior comprometimento de sua equipe, pois consecutivamente com metas mais altas, maiores serão as comissões.

Logo, compreende-se que, neste caso, o bom desempenho da equipe resulta em maiores bonificações financeiras, dias de folga como premiação e também resulta na satisfação de um trabalho bem feito. Noutras palavras, por meio de um bom desempenho, o colaborador passa a ser visto como alguém importante e valorizado dentro da organização, trazendo resultados que auxiliam a empresa a alcançar seus objetivos. 


\section{SUPORTE ORGANIZACIONAL X DESEMPENHO PROFISSIONAL ESPERADO}

A partir desta seção, tem-se uma análise do entrelaçamento do suporte organizacional com o desempenho profissional esperado pela empresa e o quanto um influencia na melhoria do outro. Assim, conforme mencionado anteriormente, a empresa oferta ferramentas necessárias, para que seus colaboradores possam desempenhar suas funções com maior eficiência. A flexibilidade de horários na jornada de trabalho proporciona ao funcionário uma conciliação maior entre a vida profissional do pessoal, fazendo com que estes não se sintam supercarregados com o trabalho, diminuindo os níveis de estresse e possibilitando um comprometimento maior na realização de suas atividades.

Noutras palavras, pode-se argumentar, também, que uma empresa ao ofertar um ambiente de descanso, onde seus colaboradores possam fazer suas refeições, contribui para uma melhor disposição física do mesmo, condicionando este a ter um maior aproveitamento do seu tempo de intervalo, o que reflete num rendimento maior na execução das atividades e consequente uma melhoria considerável no desempenho esperado deste.

No que tange ao treinamento ofertado pela empresa aos colaboradores, nota-se que além do funcionário do stand, nenhum outro recebe treinamento na empresa. Assim, a falta deste afeta as atividades e condiciona a execução das tarefas de forma insuficiente, colocando em questionamento a qualidade e assertividade das informações e serviços prestados por estes, frente aos clientes. Neste sentido, seria prudente a organização realizar treinamentos e capacitações a todos os seus colaboradores, podendo estes serem de forma online e muitas vezes sem custo algum para a empresa, pois atualmente existem muitas plataformas gratuitas com palestras e cursos de aperfeiçoamentos profissionais.

Como forma de melhor demonstrar a relação do suporte ofertado pela empresa com o desempenho profissional esperado, no Quadro 1 tem-se, uma relação proposta pela literatura em detrimento da oferta ou não pela empresa, bem como que desempenho profissional esperado com este, a partir das observações realizadas no ambiente empresarial.

Quadro 1 - Comparativo do suporte ofertado com o desempenho esperado.

\begin{tabular}{|l|c|l|}
\hline \multicolumn{1}{|c|}{$\begin{array}{c}\text { Práticas de suporte } \\
\text { proposto pela literatura }\end{array}$} & $\begin{array}{c}\text { A empresa oferece } \\
\text { aos colaboradores? }\end{array}$ & O desempenho profissional que se espera com esse suporte \\
\hline Treinamento. & Não & $\begin{array}{l}\text { Maior confiança na execução das tarefas. Segurança em propor } \\
\text { melhorias para a empresa }\end{array}$ \\
\hline Desenvolvimento e carreira. & Sim & $\begin{array}{l}\text { Maior comprometimento do colaborador acerca da organização em fazer parte da organização e maior desempenho } \\
\text { profissional }\end{array}$ \\
\hline $\begin{array}{l}\text { Incentivos, remuneração e } \\
\text { gestão de desempenho. }\end{array}$ & Sim & Maior comprometimento e satisfação do colaborador. \\
\hline $\begin{array}{l}\text { Conforto, condições de trabalho } \\
\text { e bem-estar. }\end{array}$ & Sim & Maior autonomia e confiança para desempenhar suas atividades. \\
\hline $\begin{array}{l}\text { Relacionamento, comunicação } \\
\text { e participação. }\end{array}$ & Não & Maior satisfação e frequência no trabalho. \\
\hline Saúde. & Sim & Maior confiança na organização. \\
\hline Justiça. & Fonte: & da pesquisa. \\
\hline
\end{tabular}

Fonte: Dados da pesquisa. 
De acordo com o Quadro 1, tem-se exposto, conforme observado, algumas práticas de suporte proposto pela literatura, comparando com a disponibilidade desta pela empresa em análise, com o desempenho esperado. Assim, no que tange o treinamento, este refere-se às oportunidades de capacitação profissional oferecidas pela organização aos seus funcionários, com a finalidade de corrigir e aprimorar as suas competências. No entanto, este não é ofertado pela empresa e na ausência do mesmo, os colaboradores podem se sentir inseguros na realização de suas tarefas, deste modo não desempenhando bem as suas atividades.

Desenvolvimento e carreira referem-se às ações organizacionais que indicam preocupação organizacional com o futuro profissional e pessoal dos funcionários. Este suporte proporciona satisfação do colaborador em fazer parte da organização, deste modo, desencadeando um maior comprometimento do mesmo. Percebe-se assim que este não é oferecido como suporte para os colaboradores.

Incentivos, remuneração e gestão de desempenho referem-se às estratégias empregadas pela organização para manter e melhorar os níveis de desempenho dos seus funcionários e à qualidade das políticas e práticas organizacionais relativas à administração de salários. Já o conforto, condições de trabalho e bem-estar referem-se ao gerenciamento da jornada de trabalho e das condições físicas e materiais dos ambientes de trabalho.

Relacionamento, comunicação e participação estão interligados com a qualidade do relacionamento interpessoal na organização. Já os benefícios de saúde, os quais não são ofertados pela empresa, referem-se às ações organizacionais que propiciam salários indiretos e possibilitam acesso a serviços de assistência médica. Por outro lado, a justiça refere-se à qualidade dos procedimentos e critérios de distribuição de benefícios e recompensas organizacionais. Por fim, vale ressaltar que os funcionários bem capacitados e valorizados desempenham suas funções com maior autonomia e confiança, desta forma, proporcionando maiores resultados para a organização. Além disso, de acordo com os suportes oferecidos pela organização aos colaboradores, se espera determinado desempenho profissional deste, pois ao que se percebe, a empresa em análise funciona como um sistema de compensação, esperando do profissional um retorno pelo que foi ofertado.

\section{CONSIDERAÇÕES FINAIS}

A presente pesquisa possibilitou investigar como o suporte organizacional influencia no desempenho profissional dos colaboradores de uma empresa privada da região central do Rio Grande do Sul. Torna-se relevante destacar, que neste caso, para a empresa em análise, a percepção do suporte organizacional observado deu-se termos de equipamentos, máquinas e materiais, bem como a percepção de condições estruturais. Além disso, a recompensa financeira quando se trata de remuneração e benefícios em contrapartida ao esforço dispendido no dia a dia do trabalho é satisfatória para os colaboradores. 
Ainda, percebeu-se que, a prática de dar feedbacks é vista como um suporte importante, uma vez que é por meio deste que há o alinhamento de expectativas entre o colaborador e a organização no que tange o desempenho das atividades. Conforme observado, esta prática é frequente na empresa e auxilia os colaboradores no direcionamento de suas atividades.

Outro ponto observado, e que se pode concluir neste estudo é que os colaboradores se sentem satisfeitos em relação aos suportes organizacionais já ofertados pela empresa. No entanto, a falta de treinamento muitas vezes pode comprometer a entrega das atividades e prejudicar seu desempenho profissional esperado, fazendo com que os colaboradores percam alguns benefícios advindo por meio de uma melhor execução das tarefas.

Conclui-se também, que a empresa não dá um suporte aos colaboradores no que diz respeito às questões de saúde e qualidade de vida, bem como o desenvolvimento de carreira. Sugere-se neste caso, que a não oferta destas práticas pode estar ligado a estrutura organizacional pequena que comporta a empresa, não havendo espaço e condições financeiras para a ocorrência destas. Ainda assim, isto prejudica o desempenho profissional dos colaboradores.

Sob este viés, conclui-se também, que os resultados aqui encontrados emergem para a empresa em alguns pontos fracos nas rotinas de trabalho, já que as avaliações não foram muito satisfatórias no fator treinamento, saúde e desenvolvimento e carreira. Assim, sugere-se para a empresa em análise a elaboração de um planejamento estratégico voltado para a gestão de pessoas, o qual inclua ações estratégicas que transformem estas fragilidades em pontos fortes.

Quanto as limitações encontradas neste estudo, por se tratar de um estudo de caso e a coleta de dados ocorrer pela técnica de observação, notou-se que o comportamento dos colaboradores e gestores, mediante a presença do pesquisador tende a ser influenciado. Ainda, o acesso a muitas informações que seriam importantes para um maior aprofundamento deste estudo, limitou-se ao que era repassado pelos gestores, não possibilitando uma visão mais holística da organização.

Por fim, a pesquisa alcançou o objetivo estipulado e a problemática levantada, por meio dos resultados alinhados com as teorias estudadas a respeito do suporte e desempenho profissional, além de trazer dados importantes para serem explorados pela organização no que tange o suporte organizacional, uma vez que este reflete consideravelmente no desempenho de seus colaboradores.

\section{REFERÊNCIAS}

ABBAD DE OLIVEIRA. G. Percepção de suporte organizacional: desenvolvimento e validação de um questionário. Revista de Administração Contemporânea, v. 3, n. 2,1999. 
AMARANTE, ZAVIANI. P. F. O impacto das práticas de gestão do conhecimento no desempenho organizacional: um estudo em empresas de base tecnológica. Perspectivas em Ciência da Informação, v. 24, n. 1, p. 61-83, 2019.

ANDRADE, R. M. Qualidade de vida no trabalho dos colaboradores da empresa Farben S/A indústria química. Universidade do extremo sul catarinense - unesc: Criciúma, 2012.

BRAS FERREIRA, L. A técnica de observação em estudos de administração. ANPAD, Rio de Janeiro, 2012.

BERGAMINI, C.W. Motivação nas organizações. Editora Atlas, 4. ed., 1997.

COELHO JÚNIOR, F. A. Suporte à aprendizagem, satisfação no trabalho e desempenho: um estudo multinível. (Tese de Doutorado). Universidade de Brasília: Brasília, 2009.

COSTA. P. Motivação no Trabalho. RH Portal, 2015. Disponível em: https://bit.ly/3wbIXOv. Acesso em: 17 nov. de 2020.

FORMIGA, N. S.; FREIRE, B. G.O.; BATISTA, P. F. A.; ESTEVAM, I. D. Suporte organizacional e autoestima em funcionários de organizações públicas e privadas no Brasil. Revista Psicologia, v. 1, p. $1-18,2018$.

GABLER, N. Vida, o filme: como o entretenimento conquistou a realidade. São Paulo: Companhia das Letras, 1999.

GIL FLORES, J. Análisis de datos cualitativos. Aplicaciones a la investigación educativa. Barcelona: PPU, 1994.

GROTE, D. O indicador de performance: perguntas e respostas. Rio de Janeiro: Campus, 2006.

HOCAYEN SILVA, Antônio João. Metodologia de pesquisa: conceitos gerais. Unicentro: Paraná, 2014.

JAWAHAR, I. M.; HEMMASI, P. Perceived organizational support for women's advancement and turnover intentions: the mediating role of job and employer satisfaction. Women in Management Review, v. 21, n. 8, 2006. 
KANAN. L. A. Suporte organizacional sob a perspectiva de professores gestores. Campus UTPL, 2018.

PASCHOAL, T. Bem-estar no trabalho: relações com suporte organizacional, prioridades axiológicas e oportunidades de alcance de valores pessoais no trabalho. Tese de Doutorado. Universidade de Brasília, Brasília: Distrito Federal, Brasil, 2008.

PASCHOAL. T. Felicidade no trabalho: relações com suporte organizacional e suporte social. Revista de Administração Contemporânea. v. 14 n. 6, 2010. 